\title{
Study of cardiac arrhythmias and other forms of conduction abnormality in newborn infants
}

\author{
D P SOUTHALL, M J ORRELL, J F TALBOT, R J BRINTON, D G VULLIAMY, A M JOHNSON, \\ B R KEETON, R H ANDERSON, E A SHINEBOURNE
}

British Medical fournal, 1977, 2, 597-599

\begin{abstract}
Summary
In an unselected population of 2030 newborn infants studied by electrocardiography (ECG) between April 1975 and April 1977, 35 were found to have arrhythmias or other cardiac conduction abnormalities. Further investigation by means of 24-hour ECG monitoring showed that apparently serious tachyarrhythmias, such as ventricular tachycardia and slow heart rates associated with sinoatrial block, may be present without clinical disturbance in some newborn babies. Six infants had both bradycardia and tachycardia in the 24-hour recording, although the screening ECG had shown only one of these abnormalities. The alarming ECG appearance of some of the arrhythmias suggested a possible aetiological link with some unexplained sudden infant deaths: a multicentre study could determine this more readily and is therefore recommended.
\end{abstract}

Royal Crescent Cottage, Weymouth, Dorset

D P SOUTHALL, MB, MRCP, family practitioner

M J ORRELL, MB, MRCGP, family practitioner

J F TALBOT, MB, DRCOG, family practitioner

R J BRINTON, MB, BS, family practitioner

West Dorset Hospitals

D G VULLIAMY, FRCP, DCH, consultant paediatrician

Wessex Regional Cardiothoracic Centre, Western Hospital, Southampton

A M JOHNSON, MD, FRCP, consultant cardiologist

Brompton Hospital, London

B R KEETON, MD, MRCP, senior registrar in paediatric cardiology

R H ANDERSON, MD, MRCPATH, senior research fellow

E A SHINEBOURNE, MD, MRCP, consultant paediatric cardiologist

\section{Introduction}

In a previous study we examined 818 neonatal electrocardiograms (ECGs) and found 12 with conduction abnormalities. ${ }^{1}$ We have now studied a further 1212 babies and performed a 24-hour ECG recording on any baby with an abnormality and on a control group. We report here the findings and discuss their possible importance and management.

\section{Patients and methods}

Between 1 April 1975 and 31 August 1976, a 12-lead ECG, including a 10-second rhythm strip, was obtained from all babies aged 6 to 9 days who were born in the Dorchester and Weymouth maternity units and had remained in hospital till that time. This excluded babies discharged at 48 hours (about one-third of the total). From 1 September 1976 all 717 babies born in these units were studied within the first three days of life. Those with an arrhythmia in the standard ECG were monitored for 24 hours with a single-channel Medilog cassette recorder (Oxford Electronics Co Ltd). Serial recordings were then made at weekly intervals until stable sinus rhythm was seen. A 24-hour record was also taken from 80 full-term babies born in the same units who had normal screening ECGs. Seventy-five of these recordings were made between 12 hours and 8 days of age, and the other five between 9 days and 6 weeks of age.

The 24-hour tapes were analysed by means of a playback system and arrhythmia detector. The Medilog recorder and analyser incorporated a Synclock system, which provides a reference time signal. This ensured that variation in tape speed did not produce artefactual rhythm disorders. Mothers could handle their babies in the normal way while records were being taken and were asked to note their babies' activities during the recording period.

\section{Results}

Of the 2030 neonates screened, 35 had arrhythmias or conduction abnormalities, an incidence of 1 in 58. Details of the 12 disorders detected in the 818 infants in our preliminary study are not repeated here. The subsequent 1212 infants included 23 with conduction abnormalities (table). Twenty infants had cardiac arrhythmias, including 14 with atrial, junctional, or ventricular extrasystoles; two 
Conduction abnormalities detected in 23 infants

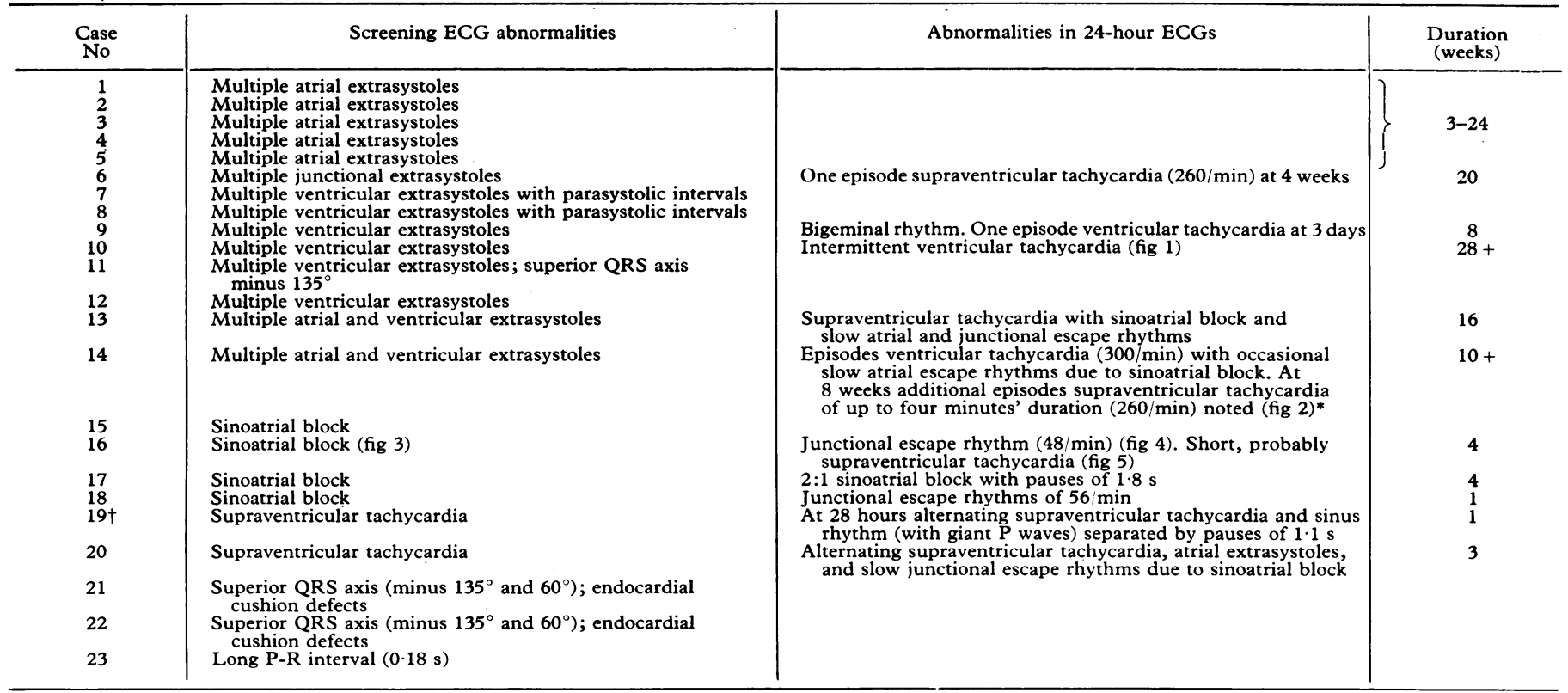
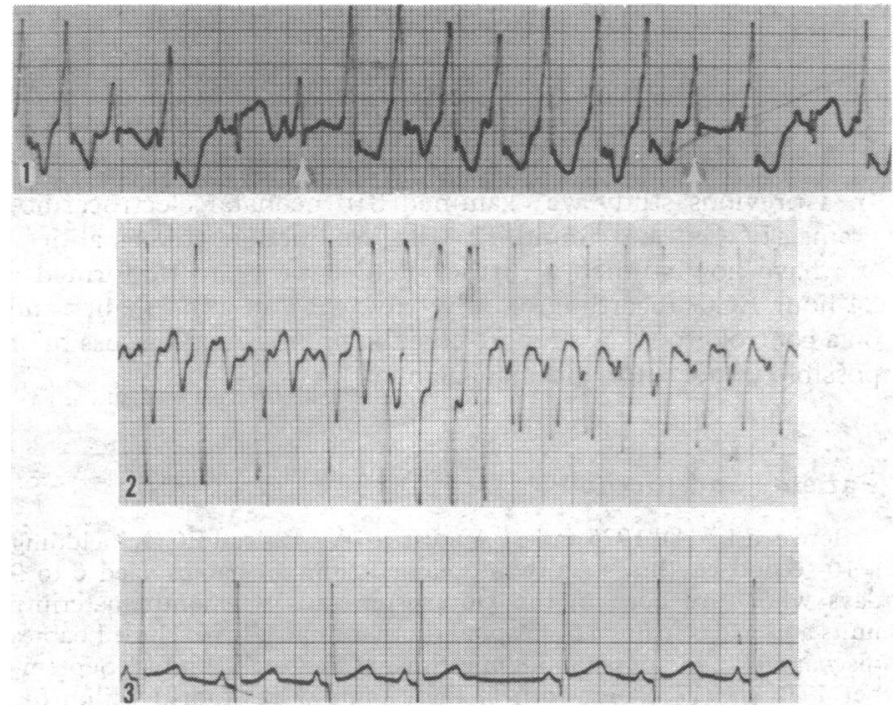

with supraventricular tachycardias; and four with sinoatrial block-a disorder that had not been detected previously. Four infants, including one with an arrhythmia, had other forms of conduction disorder. Three had a superior axis (possible left anterior hemiblock) and one a long P-R interval (possible atrioventricular block).

Twenty-four-hour recordings showed more-complex ECG changes (table, figs 1-5) and allowed the duration of the arrhythmias to be measured more accurately. Slow heart rates associated with sinoatrial block were most prominent during the first two weeks of life; the tachyarrhythmias persisted for one to six months.

Twenty-four-hour monitoring of the control group showed sinus rhythm with continuously varying R-R intervals in all cases. Sinus tachycardia up to 220 beats/min and sinus bradycardia down to 59 beats/min also occurred. Sudden changes in heart rate were seen in most infants. Alterations in P-wave configuration sometimes with but often without changes in rate occurred in 25 babies. Atrial escape beats often appeared with heart rates of less than 80 beats $/ \mathrm{min}$. In one infant a relative bradycardia of 73 beats $/ \mathrm{min}$ was associated with a junctional escape focus. Reference to the log kept by mothers during the recordings showed that sudden changes in rate and sinus
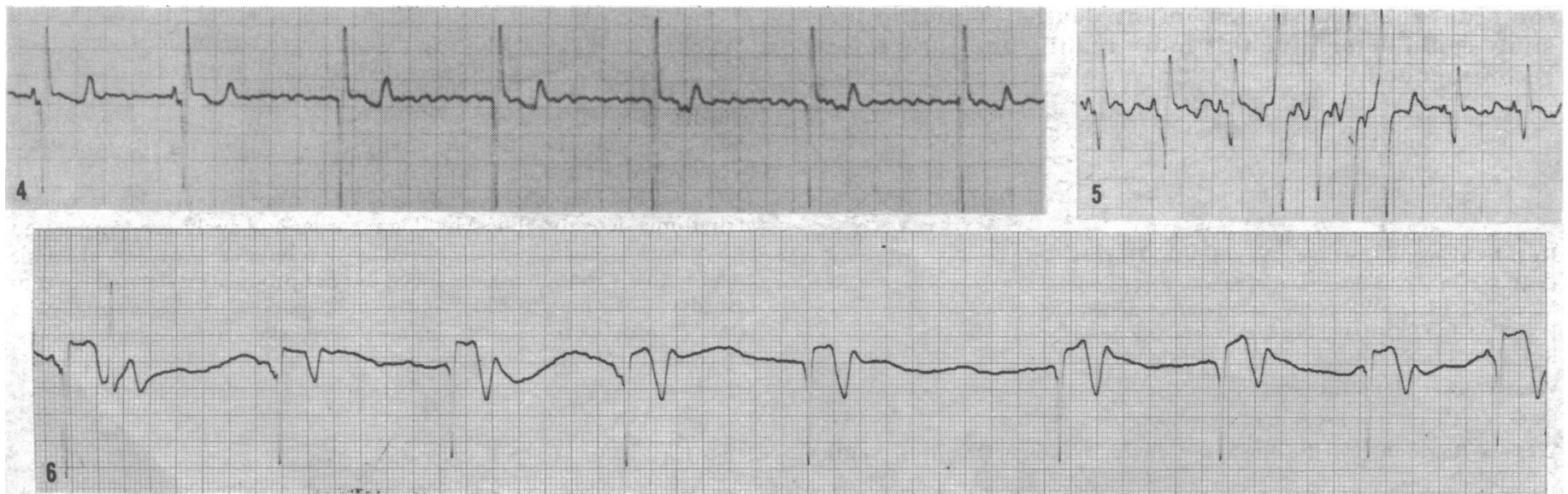

FIG 1-Case 10. Age 4 days. Twenty-four hour record showing intermittent ventricular tachycardia. Fusion beats arrowed. FIG 2-Case 14 . Age 8 weeks. Twenty-four hour record showing multiple atrial extrasystoles followed by episode of probable ventricular tachycardia and leading in to continuous supraventricular tachycardia. FIG 3-Case 16. Age 2 days. Screening ECG showing sinoatrial block. FIG 4-Case 16. Age 3 days. Twenty-four hour record showing probable sinoatrial block with slow junctional escape rhythm. FIG 5-Case 16. Age 3 days. Twenty-four hour record showing short episodes of probable supraventricular tachycardia (despite difference in initial vector of QRS complex compared with sinus beats). FIG 6-Case 24. Age 6 days. Twenty-four hour record showing extrasystoles, complete sinoatrial block, and slow junctional escape rhythm. There is an asystolic pause of $1.8 \mathrm{~s}$ before sinus rhythm returns. 
bradycardia occurred mostly at night during sleep or around the time of feeding

Nine control infants had occasional atrial extrasystoles and one had isolated ventricular premature beats. Two infants in the control group showed definite arrhythmias. The first (case 24) had two episodes of complete sinoatrial block with a very slow junctional escape rhythm (fig 6). The second (case 25 ) had multiple ventricular extrasystoles and two short episodes of paroxysmal tachycardia with normal QRS duration. Subsequent 24-hour recordings were all normal.

\section{Discussion}

These findings confirm that cardiac conduction abnormalities may occur without clinical disturbance in newborn infants. Twenty-four-hour recordings allowed us to study in more detail the cardiac rhythm of apparently normal newborn infants as well as those with arrhythmias.

In the 80 control infants sudden changes in heart rate, abrupt bradycardias simulating sinoatrial block, and prevalent atrial escape rhythms were found. Changes in $\mathrm{P}$-wave configuration without changes in rate have previously been reported ${ }^{2} 3$ and probably occur because of differences in the generation and exit of the impulse from within the sinus node. ${ }^{1}$ The presence of two definite arrhythmias in the control group shows, not surprisingly, that a screening ECG is not a sure way of detecting all abnormalities. Twenty-four-hour recordings are not a practical proposition on a large scale in the newborn, and investigations to decide on the optimum timing and duration of the screening ECG are underway. The aetiology of the arrhythmias is uncertain but autonomic disturbances, as suggested by Schwartz," may be important, particularly in those infants with slow rates associated with sinoatrial block. Autonomic effects may also be related to the changes in rhythm encountered in the control group.

Three infants had ventricular and five supraventricular tachycardia. Tachyarrhythmias, especially when associated with pre-excitation, have been well documented in infancy ${ }^{6}$ but usually they are reported because of their severe clinical effects. Despite the alarming ECG appearances most infants in this series were well. One infant (case 19) was noted in utero to have a tachycardia. Radford et al recently reported 10 cases of paroxysmal atrial tachycardia in fetuses. Because of apparent fetal distress caesarean section was performed in four of their cases. Three babies were born with oedema, ascites, and other evidence of cardiac failure. This work suggests that arrhythmias similar to those found in our study do occur in utero and may be an important cause of perinatal morbidity and possibly intrauterine death. Six infants showed sinus node malfunction typical of the tachycardia-bradycardia (sick-sinus) syndrome." Treatment of the bradycardia may make the tachycardia worse and vice versa." Particular care is therefore needed in the neonate when treating this combination of arrhythmias with drugs.

Conduction abnormalities similar to those found in this newborn population are known to be associated with sudden death in childhood. ${ }^{10}$ Recently a 7-year-old child was described"1 who died from a ventricular arrhythmia of unknown origin. Though previously thought to be rare in childhood, six infants in our series had similar ventricular arrhythmias, including three with ventricular tachycardia. An important part of this study was therefore to determine whether any of the ECG abnormalities we found could be linked with the syndrome of sudden and unexplained infant death. Since our previous report there have been no examples of this syndrome in infants studied by us. We therefore have no direct evidence of an association between the two. Two features of the natural history of conduction abnormalities, however, may suggest a possible link with sudden infant death.

Firstly, the syndrome occurs predominantly during the first six months of life and therefore has a time scale similar to the conduction abnormalities described here. Most of the arrhythmias were also present in the first two weeks of life, and the cases with sinoatrial block were most abnormal at this time. Sudden unexpected deaths in this period, however, are not necessarily assigned to the sudden infant death syndrome. None the less, careful research by Emery ${ }^{12}$ has shown that the syndrome does occur in the first week of life but is included in tables of perinatal mortality. This observation is supported by three sudden and unexplained deaths that had occurred in the Dorchester maternity unit since 1972. These babies, who were under the supervision of experienced midwives, were thought to be well in the few hours before death. Secondly, 24-hour recordings have shown that the arrhythmias occur more often during sleep and tend to be more severe at night (similar to the findings of Goldblatt ${ }^{13}$ ). Guilleminault et al ${ }^{14}$ suggested that in "near-miss" sudden infant deaths there are centrally mediated autonomic disturbances during sleep that may be transmitted to the circulatory or respiratory system.

Definite evidence of a link between some sudden infant deaths and abnormalities of cardiac conduction could be provided by a statistically significant fall in the incidence of these deaths as a consequence of the detection and treatment of certain ECG abnormalities. Because of the small number of births in our area a multicentre study would more readily determine this and is therefore recommended.

We thank Dr D A Chamberlain for help in interpreting difficult ECGs. Drs R Purvis and P G B Johnston gave invaluable support in the difficult clinical management of infants with arrhythmias. Mrs $\mathrm{J} M$ Andrews performed the screening ECGs, Dr P J Mitchell analysed the 24-hour recordings, and Mrs J J M Crosbie did the secretarial work. The project was supported by grants from the British Heart Foundation and the Wessex Regional Health Authority. Generous donations were also given by the Weymouth Round Table and Licensed Victuallers. We also thank Colin Rogers and the medical art and photography departments of the Royal Marsden Hospital for the illustrations.

Requests for reprints should be addressed to: Dr D P Southall, Dorset County Hospital, Princes Street, Dorchester, Dorset DT1 1TS.

\section{References}

I Southall, D P, et al, British Medical fournal, 1976, 2, 615.

2 Michaelsson, M, Acta Paediatrica Scandinavica, 1959, 48, suppl, p 108.

${ }^{3}$ Morgan, B C, and Guntheroth, W G, fournal of Pediatrics, 1965, 67, 1199.

4 Brody, D A, Woolsey, M D, and Arzbaecher, R C, Circulation, 1967, 36, 359.

Schwartz, P J, American Fournal of Medicine, 1976, 60, 167.

${ }^{6}$ Lubbers, W J, et al, European fournal of Cardiology, 1974, 2, 91.

7 Radford, D J, Izukawa, T, and Rowe, R D, Archives of Disease in Childhood, 1976, 51, 613.

${ }^{*}$ Short, D S, British Heart fournal, 1954, 16, 208.

${ }^{9}$ British Medical fournal, 1977, 1, 4.

10 Wennevold, A, and Sandøe, E, 1970, in Symposium on Cardiac Arrhythmias, ed E Sandøe, E F Flensted-Jensen, and K H Olesen, p 767. Astra, Södertälje.

${ }^{11}$ Radford, D J, Izukawa, T, and Rowe, R D, Archives of Disease in Childhood, 1977, 52, 345.

12 Emery, J L, Recent Advances in Paediatrics, No 5, ed D Hull. London, Churchill Livingstone, 1976.

${ }^{13}$ Goldblatt, E, Paediatric Cardiology. London, Churchill-Livingstone. In press.

14 Guilleminault, C, et al, Lancet, 1976, 19, 1326.

(Accepted 8 fuly 1977) 